JOURNAL OF MANAGEMENT (2021), VOL. 4(1), 81-93

\title{
BBS Second Year English Course in TU for the Development of Business Communication Skills
}

\author{
Dr. Ramji Timalsina \\ Lecturer \\ Department of English, Mahendra Multiple Campus, Dharan, \\ Tribhuvan University, Nepal \\ Email: ramjikoshi@gmail.com \\ DOI: https://doi.org/10.3126/jom.v4i1.38682
}

\begin{abstract}
Skill for effective communication is an essential quality of a business professional. A course on business communication needs to help them develop such a capacity. The course of English entitled 'business communication' prescribed in BBS second year in Tribhuvan University has intended to achieve this goal. On this background, this article analyses how the combination of the contents, language skills and recommended pedagogical approach of tis course is useful to achieve the intended goal of the curriculum. The study is based on Content and Language Integrated Learning (CLIL) principles which argue that language learning should be relevant to the future career of the learners. Only such a course can encourage the learners' involvement and makes a language class lively and goal oriented. Seen from this perspective, the course under analysis connects the value of English with professional competence with its focus on communication, collaboration, critical thinking, and creativity of its learners. The task based learning pedagogical approach makes both the students and teachers active in the classroom and students continue learning language even beyond the classroom set up. Such a course is useful for career based studies.
\end{abstract}

Keywords: business communication, business professional, content and language integrated learning, pedagogy, use of technology in teaching

\section{Introduction}

\section{Background}

English is a compulsory course in the Bachelor level in the study of management in Tribhuvan University, Nepal. The Faculty of Management (FOM), has set English course to fit in its "ultimate objective of educating students for professional pursuits in business, industry and government". In keeping with this general objective, 
the goal of the curriculum is to "prepare professional managers capable of handling business in a dynamic global environment of organized activity" (FOM 2013, p. 1). Aligned with these visions, the objective of the BBS programme at the FOM is "to develop students into competent managers for any sector" (p. 2). The course of English entitled "Business Communication" in the BBS Second year designed and brought into application from 2013 aligns with the same objective of the curriculum.

The curriculum mentioned that the aim of this course is to make its learners capable of handling the communicative activities in the business workplace. So, the curriculum declared that this course provides “clear learning aims, targeted to learners' needs; the grammar, vocabulary, and functions necessary for learners to become operational in a range of professional and social situations". For this it has adopted "a new approach to grammar which guides learners to work out rules of meaning and usage; strategies for effective vocabulary learning; and authentic materials to reflect learners' needs and expectations" with the prescription of the course under "Business English" based on the course book International express: Student's book upperintermediate. The curriculum further declared that this course is for "mature learners who need English as a language of international communication in both professional and social contexts". So they "need to review and build on the grammar they have already covered; need to develop fluency and accuracy; need to extend and develop their active and passive vocabulary". It is believed that the learners of this course "have limited time available for study; and can develop strategies to enable them to take control of their own learning" (FOM, 2013, p. 18). Thus, the curriculum demands creative involvement of the learners during the study.

To achieve its set objectives, the course has incorporated the problem-solving approach to writing skills. The course book Writing skills: A problem-solving approach has been prescribed for the accomplishment of this purpose. This section of the course concentrates on "presenting the skills students need when they write in English in business situations". Such skills include listening, speaking, reading, and writing along with the knowledge of English vocabulary and grammar that "are not specific to business communication" as the general principles of language are necessary even in business communication. Thus, the curriculum declares that "the main objectives of the course are to enable students to put ideas in order, group ideas into paragraphs, write apt introduction and conclusion, show relationship between ideas, present attitude clearly, edit out irrelevant materials, [and] punctuate correctly" (FOM, 2013, p. 19). Here, too, learners' involvement is the key to developing communicative competence. 
This arrangement has the undercurrent of thought that "good managers are good communicators and mediocre communication would hold them back despite their considerable talents" (Sekar, 2019, p. 3) and "[t]he quality of any organization be it business, social, military, or government, is enhanced or limited by the quality of its leadership communication" (p. 4). Such skills will help the learners to get a good job: "As English is becoming the global language in communication, business, science, technology and industry, it plays a vital role in gaining job opportunities". It also has the underlying belief that "[a]s there is a lack of linguistic proficiency, poor communicative and personality skills it becomes very difficult for the young graduates to express their thoughts in an effective manner" (Sivaranjani \& Ajitha 2016, p. 39). This view shows that the students of business studies need to learn practical language skills.

\section{Statement of the Problems}

English courses in different disciplines have their own preferences. Such preferences have contributed to the development of CLIL (Content and Language Integrated Learning). The disciplines under the management study have also followed this focus. In this context, this article deals with the issue of such integration in the English course in BBS Second Year in Tribhuvan University, Nepal. This issue is explored with the use of the following research questions:

1. What language skills are the focuses of the course?

2. How are content and language skills integrated?

3. Why is a certain pedagogical approach preferred?

\section{Objectives of the Study}

The objectives of this study are:

1. To find the language skills the course focuses on.

2. To discuss the integration of content and language.

3. To analyse the role of a certain pedagogical approach the curriculum has preferred.

\section{Review of Literature}

This section of the article reviews the reasons behind the application of communication and learners focused content in English courses in the management. To begin with, some researchers in his field have found that there is a direct connection 
between the communicative capacities of an employee with their chances of getting a good job in business market and being successful in their professional life.

Sankar and Kumar (2016) found that "English helps the people to acquire a dream job through communication skills". They found that there is a close connection between the capacity to conduct communication in English and to run a business successfully in modern day business world (p. 101). This has become even more true in the wake of "increasing globalization and internationalization, communication, and education across the borders" that has made English a key towards "better opportunities for employment, and is a dominant factor in upward mobility" (p. 102). Hussain, Ahmed and Zafar (2009) discussed the impact of rapid spread of English in connection with "the access to higher education and employment opportunities" (p. x). Their focus is on the need of any employee's "communication skills in English, irrespective of their technical and professional expertise". They claimed that "[d]egrees and qualifications without competence in English have become more of a liability than an asset". It is because English has become "a symbolic tool for the exercise of authority" as through language use and "critical language awareness, we can take control of the multiple ways in which we participate in society". They claimed that such a need of English as a means of essential means of business communication "language learning and teaching are seen in an extended context rather than a mere addition of a code for international communication (p. xi). These researchers have connected the value of English with professional competence.

To align the learning of English with the need of the business world, it should be helpful in the development of other skills along with communication competence. Halvorsen (2018) argued that the 4Cs i.e. "communication, collaboration, critical thinking, and creativity" (p. 1) should be integrated with the earning of any type for this century. The communicative capacity can be helpful in the development of other capacities under the 4Cs "since knowledge is useless unless it can be communicated effectively" (McComiskey, n.d., 5). Sekar (2019) supported this claim in connection with the need of English in the management: "The basic functions of managementplanning, organizing, staffing, directing, and controlling — cannot be achieved well without communication". For this reason, business communication is "goal-oriented in the sense that there should be a flow of information exchange between those who are holding higher positions and those who are working at subordinated positions, and between organization and trade union, and society at large" (p. 2). These scholars 
focused on the need of making the course in English in management studies practical in the career.

Sekar (2019) reviewed the trend of English courses in managerial education. His finding is: "Books published between 1995 and 2015 on various themes of business communication have ... touch[ed] upon several domains from . . . communication theories to communication skills, . . . and cross-cultural to intercultural business communication". At the same time, he found that the authors "cover interpersonal communication, group communication, written and oral presentation, and the use of electronic media" (p. 2). He further found that there is "a great range of communicative activities such as case study approach, information gaps, interviews and role plays in an attempt to encourage students to think critically, solve problems, and develop their oral communication skills". These courses aimed to show business writing different from "academic, technical, creative, and journalistic writing" (p. 3). It shows that business skill oriented English is the preference of the courses in English in recent curriculum.

Sekar's (2019) further finding is about the skills such courses focus on. He found: "Oral communication, written communication, and interpersonal communication are three major modes of business communication" that such courses help the learners to develop for their career. Such courses include the skills for developing "efficacy of oral communication" that depends on " empathy, use of visuals in presentation, quantum of information through visuals, handouts, feedback from audience, the extent to which interlocutors establish engagement with audience, interacting with audience, voice modulation, tone of voice, eye contact, and presenter's positioning in the hall". It shows that business communication skills go beyond the use of mere language; and the courses in language include the opportunities to develop these skills as well. For the development of written communication English courses "include text type (report/case study/essay/reflective discourse)" along with the skills on deciding "the length of document, structuring the argument with supporting evidence and facts for each idea, density of text, font size and style, use of reference" as well. They even include the contents and practice on interpersonal communication that "requires emotional intelligence, body language, posture, sensitivity to audience, and active listening" (10). This shows the extension of English courses for business communication.

Haase (2013) argued why such an extensive area comes under the premise of business communication. The purpose of communication is to convince the audience. 
So, "rhetoric was its earliest representative field of these studies". He classified the language employed in business communication "as a variation of the Standard English language of a special social community of professionals" (p. 55). The study of business communication should help develop skills for gaining "profits directly or indirectly" (p. 59). So, the aim of "business communication in a corporate organization can be described as the supportive actions of the conduction of business in the interest of the organization". Similarly, "[b]usiness communication as a skill of managers requires the ability to communicate the aims of management, which are planning, controlling, and decision making. So according to these functions the business communication takes place" (p. 64). Thus, he found the following courses as essentials in the study of English for business purpose: Business Communication as Technical Communications, Business Communication as Linguistic Communication , and Business Communication as Corporate Communication" (p. 80). But these discussions have not dealt with how all these skills can be developed with the use of the same course within a year. Such a possibility with the use of BBS second year English course for business communication has been discussed in this article.

\section{Research Methods and Materials}

This study is an analysis of the course on business communication. So, the primary data for the analysis is comprised of two text books prescribed for the level. The process of analysis is the discussion on content based on the established principles of business communication and its pedagogy. At first, the discussion deals with the appropriateness of the content the textbooks have incorporated. The analysis follows the principle that "the employee should be well familiar with not only the subject knowledge, but also they must be capable to deliver their knowledge via soft skills . . . [such as] language competency [and] personality traits" (Sivaranjani, 2016, p. 36). Regarding the pedagogy of business communication, it is nearly an established fact that "a task-based approach of 'learning by doing' is the need of the hour since it exploits essential and result-oriented andragogy and heutagogy of self-directed and selfdetermined learning processes lifelong" (Sekar, 2019, p. 1). Thus, the analytical discussion deals with the content coverage and pedagogy designed for the course. My experience as a teacher of this course has also been used to develop a practical example.

\section{Results and Discussion}


This section deals with the content and pedagogy of the course. At first, the management of the content and the reason behind it has been discussed. Then its pedagogical approach is dealt with before providing a practical example of dealing with the course in the real classroom set up in Tribhuvan University, Nepal.

\section{Course Content}

The textbooks of Business Communication in BBS second year in Tribhuvan University, Nepal cover business English and problem solving approach to writing skills. The content of Business English, as mentioned in the curriculum (2013), covers ten broad communicative units: Achievement, Motivation, Communication, The Future, Challenges, Psychology, Creativity, Image, Responsibility, and Security. Each unit begins with an agenda which gives details of the language to be studied in the unit. This is followed by four main parts: Language focus, Wordpower, Skills focus, and Focus on functions.

Language focus presents and practices the target grammar in a context related to the general topic of the unit. It has four stages: an introductory activity, presentation of the target grammar in a realistic context, grammar analysis, and practice.

Wordpower presents and activates a lexical set or semantic field related to the topic of the unit. At the same time it introduces a variety of strategies for organizing and learning vocabulary effectively. It has two stages: introduction of topic-related vocabulary and a follow-up practice activity.

Skill focus has longer listening and reading texts, which provide exposure to the target grammar of the unit and develop listening, speaking, and reading skills. It has three stages: a preview to introduce and stimulate interest in the topic, a task (s) to complete while reading or listening, and follow-up.

Focus on functions presents and practices basic key phrases which professionals need for socializing. There are two main stages: a range of possible exponents for students to identify, and controlled and then freer roleplay. (p. 18)

This content coverage shows that the course is organized with the practical belief that "English is an international business communication tool and it transcends cultures". It also highlights the need that " $[\mathrm{t}]$ he teaching of business English is different from that of General English in the sense that it is neither teaching just the four macro-skills nor enhancing mere business vocabulary". It is taught with the assumption that "general 
English language skills have already been acquired" by the learners and now they need to enhance their business communication skills. It is thought so because the learners of business English are "prospective entrepreneurs, managers and leaders of industries at national and international levels" and teachers and the course need to help them "acquire an international communication skill-set through English as the medium" (Sekar, 2019, p. 1). The above mentioned content of Business English help students acquire these skills.

This content also highlights the fact that

Effective communication also depends on several cultural factors. Different cultures prescribe different cultural norms to communicating. When English is used as a means of international and intra-national communication in multilingual and multicultural settings like India, graduates should be sensitive to cultural nuances. In other words, what is acceptable within one culture need not be appropriate and acceptable within another culture. Generation gap also matters. Business communication teachers should be cognizant of such cultural diversity and make learners sensitive to it. (Sekar, 2019, p. 11)

Similarly, the content of problem-solving approach to writing skills covers "the kinds of writing students in business are mostly in need of doing". Such writings that the course includes are informal letters, formal letters, reports, brochures and guides, articles instructions, writing a story, and business letters and memos (FOM, 2013, p. 19). The teacher's book provides guidelines to approach the course.

\section{Pedagogical Approach}

The curriculum has also designed the pedagogical approach to this course. It prescribes that the campuses and the teachers "should use the methods of instruction which help prepare the student for the realities of Nepalese business, industry and government in which he/she has to work". For this, it is prescribed that a combination of "lecture, group discussions, problem- solving exercises, guest lectures, practical work, and project work" essential "as approaches to learning" (FOM 2013, p. 6). To align with this need of the course delivery, the curriculum has specified different techniques for the different contents. The recommended teaching method to Business English is that "the teachers follow the ideas for teaching as given in the teacher's resource book" and the students "will be evaluated in terms of the skills presented in the prescribed book" (p. 19). The prescribed text-book has also provided some guidelines for approaching the contents. 
Similarly, the recommended teaching method for problem-solving approach to writing skill is also student centered. It is based on the belief that students learn a lot "by working together in groups to solve a problem or make a decision". For this the course instructors need to create an atmosphere so that the learners "should share their knowledge, compare their opinions, and discuss their ideas in small groups" (FOM, 2013 , p. 20). This course includes "pair and group work, peer review, and project-based learning (PBL)" as they "are excellent to support the development of collaboration and communication" (Halvorsen, 2018, p. 2). The class as a whole, comprising the teachers and the learners, can decide the process of dealing with the content of this textbook.

Such a pedagogical approach inspires the teachers and students to use "various tools, techniques, and resources [that] commensurate with learners' experience and level". It also promotes the idea that "[t] eaching should be customised through different locations and mediums such as work integrated learning (work and site placements), simulated learning (role plays), watching videos; practising in virtual world". Once there are communication tasks for the team, the study ensures "greater exploitation of interpersonal communication repertoire with each other and with learning students". It is necessary that the teacher in such a class "need to address certain issues arising out of team teaching and learning such as, some being nervous about communicating in a team, and others being over assertive acting as a barrier to the former". At the same time, the testing of written communication "should focus on style, substance, and structure, synthesis, analysis, and persuasiveness." (Sekar, 2019, p. 12). This curriculum has envisioned the same from both the students and teachers who deal with this course.

Task based learning is the central pedagogical approach to this course. It is supposed that the learners "perform tasks, solve problems, and live in a satisfying way. The tasks that they do are relevant to real-life tasks because they are organized around life or work situations" (Sekar, 2019, p. 13). Such an approach empowers the learners and helps them in their professional performance. Mok (1997) highlighted the value of this approach: "three important components of student empowerment efforts, i.e. empowerment through involvement, empowerment through partnership and empowerment through action research" (p. 305). Halvorsen (2018) adds: "All four language skills can easily be activated when students are asked to research a topic, discuss or debate that topic with peers, and write about what they find". He further highlighted an important fact that “these activities don't require high levels of English 
proficiency. Students even at lower-intermediate levels can conduct basic research and have meaningful discussions with peers about real issues." (p. 1). This course has the same philosophy about language learning.

\section{Practical Examples}

This sub-section provides one practical example each from both textbooks. At first, the example is from Writing skills: A problem-solving approach. The content of this book can be dealt in two ways: unit wise or content type wise. As each unit comprises of exercises on punctuation, scrambled sentences, linking words and phrases, attitude words and phrases and the process-based exercise of writing a particular type of business composition, one of the two approaches can be selected. If the class decides to go content type wise, exercises on punctuation from all units can be done first. Then, exercises on scrambled sentences from all units can be done. Similarly, the exercises on linking words and phrases and attitude words and phrases can be dealt with before practicing process-based exercise of writing a specific business composition.

If the class agrees to go unit wise, the class will be interesting mix of varieties of contents and their exercises. In this case, it is wise to follow the order of the unit. Here, I am presenting how a class can deal with the contents in unit one. This unit starts from a simple exercise on punctuation: use of capital letters. As it is an exercise on low level skill for a learner of English, students can be asked to complete the exercise within five minutes in the class. This can be given as an individual or a group exercise. The teacher can go on monitoring how the students are involved in the exercise. When everybody in the class completes the exercises, one student can report the answer to the class. The class can correct if the reporter is wrong or can ask the question if they are confused. If there is disagreement in the class, the teacher can facilitate them and make them clear. Once the first exercise is done, the class can proceed to the second one under the same title 'Punctuation'. The same process can be repeated here, too.

After the exercises on punctuation are done with, the class can go to scrambled sentences. It is appropriate to let the students try on their own. It is good to let students work in the group. As this unit is on writing an informal letter, all the scrambled sentences are to be arranged in such a way that their right order will prepare an informal letter. Then, one of the groups will be allowed to report its answer. If other groups have the difference, they will report their answers. After the reporting is over, the teacher can let the class finally work on it. If there prevail some disagreements, the teacher will finally give her version. These two headings are enough for an hour class 
time. For the day, two other headings on linking words and phrases and attitude words and phrases can be given as home assignments.

In the next class, the students will, at first, compare their answers in each group. Once they agree in the group, one of the groups will report their answer to the class. The discussion process will be the same. Then the class will discuss on the next heading 'reporting word' in the same way the previous exercises are done. With this, the discussion on grammatical exercises is to be done. Then, for the second day home assignment, exercise on paragraph completion can be assigned. On the third day class, the exercise on text comparison can be discussed after the presentation of students' home assignment.

The next class day can cover exercises 8 and 9. Doing all these exercises, students will be acquainted with the nature of language used in informal letter writing and the format of the letter. Then, the final exercise in the unit can be done. It contains questions/ideas for some informal letters. Students can be given the opportunity to choose a question for their group. Once they choose the question, they can be given the time for brainstorming for the writing. Each student's ideas can be shared in the group and with this they will write a letter individually. Once they come to the class with the letter, again each group will listen to each of its member's writing to find the best letter in the group. When each group decides the best of the writing for the day, each group will present their letter in the class. It is how, unit one can be done with complete involvement of the student and the teacher being just a facilitator in their learning. The same process can be used for each unit in this textbook.

Students' active involvement can be encouraged in the teaching of International express, too. As this textbook is directly connected with business English, many business communication skills can be developed during the learning. The content is divided into language focus, word power, skill focus, and focus on function. And the units are planned according to the necessity of business students: achievement, motivation, communication, the future, challenges, psychology, creativity, image, responsibility and security. Development of word power and grammar correctness, reading on business related short texts, writing with the focus of contents and situations related business and language functions are integrated in this textbook. So, the teacher needs to encourage students to work on their own, individually or in the group, so that they can acquire the intended skills. Students' presentation in different forms will consolidate all skills. 
This textbook has included related pictures in most of the discussions. This inclusion motivates students to engage in the talks on the topic. Their talks will be about the business and business people. The exercises also demand the same. They need to read, comprehend, think critically and creatively, and discuss to answer the questions on each of the exercises. These involvements prepare them for finding out their own topic for discussion and for research in a long run. When the half of the textbook is done, it is good to let the learners choose a topic in a group for a half an hour oral presentation. The instructor can facilitate them.

It is helpful for them to find a topic form the book itself or the topics related to the content they deal with in the text. Then, a week can be used to discuss and prepare for the presentation. The presentation can be of competitive nature so that each group will put all their efforts to make it better than the other groups. They should prepare the power point presentation that will be done in the presence of all their classmates and the campus authority. There will be judges to decide the order of good presentation. This arrangement can further encourage them to involve themselves in the job. Once they accomplish the presentation, they are already ready for good business communication.

\section{Conclusion}

The course of business communication in BBS Second Year in Tribhuvan University has the combination of business language and professional communication skills supported with student centered pedagogy. Such a combination connects the value of English with professional competence instilling the basic skills on communication, collaboration, critical thinking, and creativity in the learners. The course is a support to develop oral, written and interpersonal communications that help the learners in their career. This course shows that business communication skills go beyond the use of mere language so it is necessary to acquaint business professionals to different modes of communication with the use of English that is the means of an international business communication tool that transcends cultures. The pedagogy with its focus on the combination of lecture, group discussions, problem- solving exercises, practical work, and project work is leaners' task based. The application of the course in the real classroom has shown that all four language skills can easily be activated when students are asked to research a topic, discuss or debate that topic with peers, and write about what they find. Their use of English as a medium for all classroom and outsideclass group activities supports their learning of English for business communication. 
The role of teachers in the management of the classroom activities makes a great difference in students' learning.

\section{References}

Coe, N., Rycroft, R. \& Ernest, P. (1983). Writing skills: A problem-solving approach. Cambridge University Press.

Haase, F. A. (2013). Business Communication and Globalized English: Recent Definitions and Applications of a Concept across the Corporate World. Fonseca, Journal of Communication, 6, 53-85.

Halvorsen, A. (2018). 21st Century Skills and the "4Cs" in the English Language Classroom. University of Oregon. https://creativecommons.org/licenses/by/4.0/

Harding, K. \& Wallwork, A. (2007). International express: Student's book upperintermediate. Oxford University Press.

Hussain, N., Ahmed, A., \& Zafar, M. (Eds.). (2009). English and empowerment in the developing world. Cambridge Scholars Publishing.

Manuja, A. (2016, July). Empowerment through Language in the Tradition of the Confessional Poetry of Kamala Das. Language in India, 16(7), 41-47. www.languageinindia.com

McComiskey, B. (Ed.) (n.d.). English studies: An introduction to the discipine(s). https://www.amazon.com/English-Studies-Introduction-DisciplineRefiguring/dp/08

Mok, A. (1997). Student Empowerment in an English Language Enrichment Programme: An Action Research Project in Hong Kong. Educational Action Research, 5(2), 305-320. DOI: 10.1080/09650799700200024

Sankar, G. \& Kumar, S. P. S. (2016, July). English for Employability and Empowerment: A Study. International Journal of English Literature and Culture, 4(6), 100-103. DOI: 10.14662/IJELC2016.053

Sekar, J. J. (2019). Teaching Business Communication Skills: A Clarion Call. https://www.researchgate.net/publication/337111064

Sivaranjani, K., Ajitha, A. (2016). English for Empowerment. South Asian Journal of Engineering and Technology, 2(14), 35-40. 